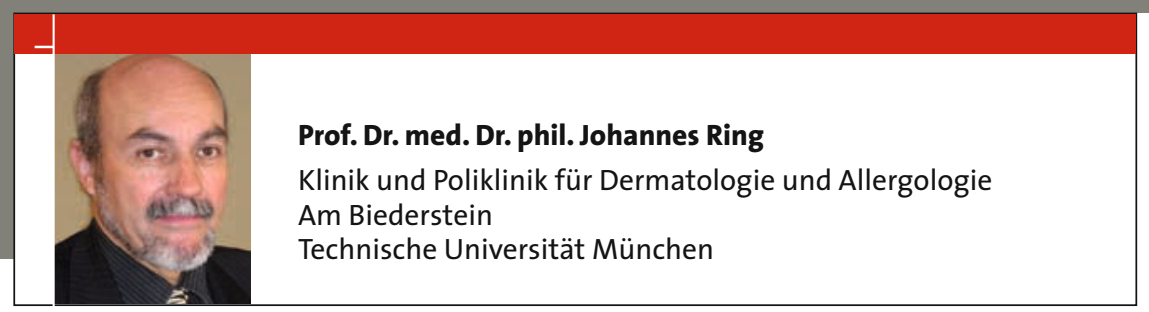

\title{
Immer mehr Kinder mit Hauterkrankungen
}

- Während die Diagnostik und Therapie kindlicher Hautkrankheiten früher auf einige spezialisierte Hautkliniken mit eigenen Kinderstationen konzentriert war, beschäftigt dieses Gebiet heute niedergelassene Haut- und Kinderärzte, aber auch die Hausärzte in zunehmendem Maße. Dies hat u.a. sicherlich mit dem starken Anstieg der Prävalenz von häufigen Hauterkrankungen zu tun, die bevorzugt oder besonders häufig im Kindesalter auftreten. Hier ist an erster Stelle das atopische Ekzem (= atopische Dermatitis, = Neurodermitis, = endogenes Ekzem) zu nennen, von dem mittlerweile $10-20 \%$ der Kinder im Einschulungsalter betroffen sind. Die Ursachen für diesen Anstieg in der Prävalenz sind keineswegs klar. Die für allergische Atemwegserkrankungen so griffige „Urwald-“ oder „Hygiene-Hypothese“, wonach frühkindlicher Kontakt mit Infektionserregern und darauffolgende Immunstimulation allergieprotektiv wirken, greift nicht für das atopische Ekzem. Auch in

ländlichen Gegenden von Zentralafrika finden sich erschreckende Häufigkeiten von sehr schweren Fällen von atopischem Ekzem, ebenso wie in den modernen „Inner-city slums“ der USA.

\section{Gendefekte mit weit reichenden Folgen}

Neben der Pädiatrie gibt es wohl kein Fach, in dem so viele genetisch bedingte Syndrome gesehen werden wie in der Dermatologie. Denn sehr viele seltene $\mathrm{Mu}$ tationen gehen mit Hautveränderungen einher, die dann die letzten diagnostischen „Clues“ geben. Die Fortschritte der molekularen Genetik machen die Kinderdermatologie derzeit zu einer besonders interessanten Fachrichtung. Fast monatlich werden neue Gen-Loci gefunden, die mit bestimmten bislang unerklärten Erkrankungen assoziiert sind und neue pathophysiologische Hinweise geben. Als Beispiel soll hier nur kurz die vor einigen Jahren entdeckte Mutation im epidermalen Protein Filaggrin erwähnt werden, die zu einem Defekt der Barrierefunktion der Haut führt. Bei homozygoter Vererbung entsteht die häufige Schuppenkrankheit „Ichthyosis vulgaris“, im heterozygoten Fall wird die Neigung zu atopischem Ekzem drastisch erhöht.

\section{Häufigstes Problem: Infektionen}

Nahezu alle Hautkrankheiten können auch im Kindesalter vorkommen, wobei sie dort manchmal besondere Charakteristika zeigen, die den Unerfahrenen verwirren. Selbst das gefürchtete maligne Melanom kann, wenn auch selten, bereits beim Kind auftreten.

Naturgemäß stehen Infektionskrankheiten durch Parasiten, Viren, Bakterien und Pilze bei Kindern und Jugendlichen an vorderster Front. Frau Prof. Hofmann beschreibt in diesem Fortbildungsschwerpunkt das scheinbar triviale Problem der Pediculosis, die vor keiner Gesellschaftsschicht halt macht und auch heute viele Eltern, Lehrer und Ärzte immer wieder vor Probleme stellt.

\section{Das Leiden der Teenager}

Im heranwachsenden Alter stellt Akne vulgaris ein großes Problem für die Betroffenen dar. In einer Lebensphase, in der sich die jungen Menschen selbst finden müssen und sehr besorgt um ihre äußere Erscheinung sind, ist der Leidensdruck durch Hautveränderungen im Gesicht immens groß. Wie dieses Krankheitsbild hervorragend und relativ einfach behandelt werden kann, wenn man es rechtzeitig erkennt, zeigt der Beitrag von Frau PD Christina Schnopp.

Die Münchner Hautklinik am Biederstein der TU München veranstaltet seit vielen Jahren ein vielbeachtetes Symposium zur „Kinderdermatologie“. Wer diese am besten kennt und versteht, wird hautkranke Kinder auch am besten behandeln. 